\section{Routine genetic testing for Asperger syndrome}

\section{To the Editor:}

We read with interest the guidelines on the clinical evaluation of the etiology of autism spectrum disorders by Schaefer et al. ${ }^{1}$ Although we congratulate the authors on the development of these guidelines, we question the need for routine studies for chromosome anomalies and fragile X syndrome for patients with Asperger syndrome (AspS). The authors state that the generally reported rate of success for identifying a specific diagnosis for evaluations of patients with various categories of autism spectrum disorders including AspS is 6-15\%. The authors cite three references in support of this. The study by Abdul-Rahman and Hudgins ${ }^{2}$ reported on 101 patients including 63 with pervasive developmental delay (PDD)/autism, 7 with AspS, 7 with autistic features, 20 with developmental delay/mental retardation, and 4 with other conditions. None of the patients with AspS had an underlying genetic diagnosis identified. Battaglia and Carey ${ }^{3}$ described 65 patients with autism, 18 with PDD-not otherwise specified, and 2 with AspS. An etiologic diagnosis was made for nine of these patients. The report does not say if either of the AspS patients had an underlying diagnosis. Schaefer and $\mathrm{Lutz}^{4}$ recommend an evaluation protocol for children with AspS or PDD yet their study reports on 32 patients with autism. None were reported to have AspS. They did however refer to six other studies in the development of their recommendations. One of the studies cited was the Battaglia and Carey ${ }^{3}$ study described above. The other studies (Refs. 5-9) were reviewed. Challman et al. ${ }^{5}$ collected data on five AspS patients but did not report those results. According to our review, we are not aware of any patients with AspS in those studies identified with a chromosome anomaly or fragile $\mathrm{X}$ syndrome.

To determine if AspS patients have been reported with a chromosome anomaly, we did a Medline search (as of July 2008), for "Asperger* Chromosome," "Asperger* Chromosomal," and "Asperger fragile X." The following cases reports were identified. Robertson et al. ${ }^{10}$ reported on a woman with Gilles de la Tourette syndrome who had developmental delays and some features of AspS or autism spectrum disorder. She had a 22q11.2 deletion. Fontenelle et al. ${ }^{11}$ reported a patient with AspS, obsessive-compulsive disorder, major depression, and 45,X/46,XY mosaicism. Tentler et al. ${ }^{12}$ described two AspS patients with balanced translocations $[\mathrm{t}(13 ; 17)(\mathrm{q} 14 ; \mathrm{p} 13)$ and $t(17 ; 19)(\mathrm{p} 13.3 ; \mathrm{cen})]$. Their second patient was previously described by Annerén et al. ${ }^{13}$ Saliba and Griffiths ${ }^{14}$ found an inherited fragile site on chromosome 2 in a patient with AspS. We found several other studies ${ }^{15-23}$ that evaluated a series of patients with autism spectrum disorders including AspS where fragile X testing and/or chromosome studies were done on all or part of the group. These studies are summarized in the Table. We also checked the Autism Chromosome Rearrangement Database. ${ }^{24}$ There were two additional unbalanced karyotypes found in AspS patients. One unpublished case with possible AspS with growth delay and dysmorphic features had a 47,XY,+ mar/46,XY karyotype. The marker was identified as 
der(7)(q11.1q11.23). Another patient described by Akefeldt and Gillberg ${ }^{25}$ had atypical autism/AspS in addition to hypomelanosis of Ito had various clonal chromosomal abnormalities. In our own laboratory, we have done chromosome studies on 24 patients whose diagnosis was stated to be AspS. All had normal karyotypes. Nineteen of these patients had fragile X molecular testing. None had fragile X syndrome. One female patient was a premutation carrier (55 CGG repeats). One male patient had 51 CGG repeats which is considered in the gray zone.

\section{COMMENT}

Most of the chromosome anomalies described are likely coincidental rather than causative, and most are considered to be normal variants that would normally not be associated with any phenotypic effects, e.g., long Y; fragile sites; single cell low grade mosaicism (query cultural artifact). The anomalies that may be clinically significant are the XYY, the $45, \mathrm{X}$ mosaic and the "major abnormality of $5 p$," the $22 q$ deletion and the mosaic derivative 7. The first two are unlikely etiologically causative of AspS, but comorbid conditions. It is difficult to comment on the significance the $5 \mathrm{p}$ abnormality without further details. The patient with $22 \mathrm{q}$ deletion had more complex problems including intellectual deficiency that would normally warrant further genetic investigations. The patient with a mosaic derivative 7 chromosome also had additional features. The chromosome anomalies seen in the patient with hypomelanosis of Ito

Table 1

Summary of published AspS case series

\begin{tabular}{ccccc}
\hline Ref. & $\begin{array}{c}\text { Total } \\
\text { patients }\end{array}$ & $\begin{array}{c}\text { AspS } \\
\text { patients }\end{array}$ & $\begin{array}{c}\text { AspS } \\
\text { abnormal }\end{array}$ & Comments \\
\hline 15 & 71 & 4 & 0 & \\
16 & 104 & $?$ & 1 & $\begin{array}{c}\text { 46,XYqs.ish (acro-p-arm+) i.e., } \\
\text { a satellited-Yq, chromosome } \\
\text { studies and subtelomeric FISH } \\
\text { done, no fragile X testing) }\end{array}$
\end{tabular}

17

$18^{a}$

82

11

100

100
1- de novo reciprocal translocation

2- inherited reciprocal translocations

1- inherited fragile $Y$

1- $21 \mathrm{p}+$, (extra material from centromere of chromosome 15)

\begin{tabular}{|c|c|c|c|c|}
\hline 19 & 30 & 2 & 0 & \\
\hline 20 & 45 & 2 & 0 & $\begin{array}{l}\text { All female patients, only fragile } \mathrm{X} \\
\text { testing done }\end{array}$ \\
\hline $21^{a}$ & 66 & 2 & 2 & $\begin{array}{l}\text { 1- "long Y" } \\
\text { 1- "single cell with XYY" }\end{array}$ \\
\hline $22^{a}$ & 20 & 3 & 2 & $\begin{array}{l}\text { 1-XYY mosaicism } \\
\text { 1- "long Y" }\end{array}$ \\
\hline $23^{a}$ & 46 & 23 & 3 & $\begin{array}{l}\text { 1-XYY mosaicism } \\
1-\mathrm{XYY} \\
1 \text { - "major abnormality of } 5 \mathrm{p} "\end{array}$ \\
\hline
\end{tabular}

${ }^{a}$ Studies from same group, possible overlap between cases. likely relate to that diagnosis rather than the AspS. ${ }^{26}$ Our finding of one fragile $\mathrm{X}$ female carrier and one male with 51 CGG repeats is interesting. Farzin et al. ${ }^{27}$ did report a higher frequency of autism spectrum disorders in fragile X premutation carriers although none were diagnosed with AspS. More research in the area is needed before testing for a fragile $\mathrm{X}$ premutation becomes a standard of practice for AspS.

One limitation of a literature review is that the diagnostic criteria for AspS used in the studies vary and have changed with time. Kopra et al..$^{28}$ described four diagnostic criteria for AspS, i.e., International Classification of Disease-10, Diagnostic and Statistical Manual of Mental Disorders-Fourth Edition, the Gillberg \& Gillberg, and the Szatmari criteria. The International Classification of Disease-10 criteria require lack of clinically significant delay in language or cognitive development in childhood. The Diagnostic and Statistical Manual of Mental Disorders-Fourth Edition criteria state that there must be no clinically significant delay in cognitive development in childhood. The other two criteria sets do not specifically require a normal IQ.

Based on our review of the literature and our own experience we recommend a detailed history and physical examination of patients with AspS. If there are dysmorphic features, intellectual impairment, or other concerns, including a family history to suggest an X-linked disorder, further investigations such as chromosome analysis, array CGH, fragile $\mathrm{X}$ testing, and possibly other genetic studies associated with X-linked mental retardation is recommended. In our opinion, routine genetic investigations in uncomplicated AspS, in the absence of any of the above findings, is not recommended. However, this group of individuals may be useful for research using genetic markers to identify genes that lead to susceptibility to autism spectrum disorders.

Bernard N. Chodirker, MD, FCCMG Albert E. Chudley, MD, FCCMG

Departments of Pediatrics and Child Health, and Biochemistry and Medical Genetics University of Manitoba Winnipeg, Manitoba, Canada

\section{References}

1. Schaefer GB, Mendelsohn NJ; Professional Practice and Guidelines Committee. Clinical genetics evaluation in identifying the etiology of autism spectrum disorders. Genet Med 2008;10:301-305.

2. Abdul-Rahman OA, Hudgins L. The diagnostic utility of a genetics evaluation in children with pervasive developmental disorders. Genet Med 2006;8:50-54.

3. Battaglia A, Carey JC. Etiologic yield of autistic spectrum disorders: a prospective study. Am J Med Genet C Semin Med Genet 2006;142:3-7.

4. Schaefer GB, Lutz RE. Diagnostic yield in the clinical genetic evaluation of autism spectrum disorders. Genet Med 2006;8:549-556.

5. Challman TD, Barbaresi WJ, Katusic SK, Weaver A. The yield of the medical evaluation of children with pervasive developmental disorders. J Autism Dev Disord 2003;33:187-192.

6. Chudley AE, Gutierrez E, Jocelyn LJ, Chodirker BN. Outcomes of genetic evaluation in children with pervasive developmental disorder. J Dev Behav Pediatr 1998;19: 321-325.

7. Kosinovsky B, Hermon S, Yoran-Hegesh R, et al. The yield of laboratory investigations in children with infantile autism. J Neural Transm 2005;112:587-596.

8. Miles JH, Hillman RE. Value of a clinical morphology examination in autism. Am J Med Genet 2000;91:245-253.

9. Shevell MI, Majnemer A, Rosenbaum P, Abrahamowicz M. Etiologic yield of autistic spectrum disorders: a prospective study. J Child Neurol 2001;16:509-512.

10. Robertson MM, Shelley BP, Dalwai S, Brewer C, Critchley HD. A patient with both 
Gilles de la Tourette's syndrome and chromosome 22q11 deletion syndrome: clue to the genetics of Gilles de la Tourette's syndrome? J Psychosom Res 2006;61:365-368.

11. Fontenelle LF, Mendlowicz MV, Bezerra de Menezes G, dos Santos Martins RR, Versiani M. Asperger syndrome, obsessive-compulsive disorder, and major depression in a patient with 45,X/46,XY mosaicism. Psychopathology 2004;37:105-109.

12. Tentler D, Johannesson T, Johansson M, et al. A candidate region for Asperger syndrome defined by two 17p breakpoints. Eur J Hum Genet 2003;11:189-195.

13. Annerén G, Dahl N, Uddenfeldt U, Janols LO. Asperger syndrome in a boy with a balanced de novo translocation:t(17;19)(p13.3;p11). Am J Med Genet 1995;56: $330-331$.

14. Saliba JR, Griffiths M. Brief report: autism of the Asperger type associated with an autosomal fragile site. J Autism Dev Disord 1990;20:569-575.

15. Herman GE, Henninger N, Ratliff-Schaub K, Pastore M, Fitzgerald S, McBride KL Genetic testing in autism: how much is enough? Genet Med 2007;9:268-274.

16. Wassink TH, Losh M, Piven J, et al. Systematic screening for subtelomeric anomalies in a clinical sample of autism. J Autism Dev Disord 2007;37:703-708.

17. Steiner CE, Guerreiro MM, Marques-de-Faria AP, Lopes-Cendes I. Laboratorial diagnosis of fragile-X syndrome: experience in a sample of individuals with pervasive developmental disorders. Arq Neuropsiquiatr 2005;63:564-570.

18. Gillberg C, Cederlund M. Asperger syndrome: familial and pre- and perinatal factors. J Autism Dev Disord 2005;35:159-166.

19. Estécio M, Fett-Conte AC, Varella-Garcia M, Fridman C, Silva AE. Molecular and cytogenetic analyses on Brazilian youths with pervasive developmental disorders. J Autism Dev Disord 2002;32:35-41.

20. Meyer GA, Blum NJ, Hitchcock W, Fortina P. Absence of the fragile X CGG trinucleotide repeat expansion in girls diagnosed with a pervasive developmental disorder. J Pediatr 1998;133:363-365.

21. Gillberg C, Wahlström J. Chromosome abnormalities in infantile autism and other childhood psychoses: a population study of 66 cases. Dev Med Child Neurol 1985; 27:293-304.

22. Gillberg C, Steffenburg S, Jakobsson G. Neurobiological findings in 20 relatively gifted children with Kanner-type autism or Asperger syndrome. Dev Med Child Neurol 1987;29:641-649.

23. Gillberg C. Asperger syndrome in 23 Swedish children. Dev Med Child Neurol 1989; 31:520-531.

24. The Autism Chromosome Rearrangement Database. Available at: http://projects. tcag.ca/autism/. Accessed August 1, 2008.

25. Akefeldt A, Gillberg C. Hypomelanosis of Ito in three cases with autism and autisticlike conditions. Dev Med Child Neurol 1991;33:737-743.

26. Taibjee SM, Bennett DC, Moss C. Abnormal pigmentation in hypomelanosis of Ito and pigmentary mosaicism: the role of pigmentary genes. Br J Dermatol 2004;151: $269-282$.

27. Farzin F, Perry H, Hessl D, et al. Autism spectrum disorders and attention-deficit/ hyperactivity disorder in boys with the fragile X premutation. J Dev Behav Pediatr 2006;27:S137-S144.

28. Kopra K, von Wendt L, Nieminen-von Wendt T, Paavonen EJ. Comparison of diagnostic methods for Asperger syndrome. J Autism Dev Disord 2008;38:1567-1573. 
ile X testing published in $2001^{1}$ and updated in $2005^{2}$ and the Genetics Practice Guidelines statement on diagnostic and carrier testing for Fragile X syndrome published in $2005 .{ }^{3}$ In the Practice Guidelines, a broad range of 41-60 trinucleotide repeats was described for the intermediate or "gray zone" in Fragile X syndrome based on a research context. That is, research groups used this broader range to identify high-risk alleles. More relevant to the clinical setting, a range of 45-54 trinucleotide repeats was quoted for the gray zone in the Technical Standards and Guidelines publication. For a summary of these ranges please see Table 1 .

Differences in the intermediate range then led to discrepancies in the reported ranges for Fragile X premutations. In the Practice Guidelines, the premutation range is characterized as 61-200 repeats, whereas in the Technical Standards and Guidelines, the premutation range is defined as 55-200 repeats. The American College of Obstetricians and Gynecologists based their committee opinion on the ACMG Practice Guidelines, leading to confusion among physicians in interpretation of Fragile $\mathrm{X}$ test reports. The ranges for intermediate and premutation Fragile X alleles quoted in the 2005 Practice Guidelines have never been used in laboratory practice. After an extensive review of the literature in 2005, the Quality Assurance Committee of the ACMG determined that no changes were required to the ranges originally published in 2001 .

In a recent article summarizing two multidisciplinary workshops focused on reproductive counseling for FMR1 premutation carriers, Wittenberger et al. ${ }^{5}$ defined the four allelic forms of FMR1 with respect to CGG repeat size. They stated that consensus has been reached, both in the literature and in the workshops regarding the size of the premutation at 55-200 repeats, and the full mutation at $>200$ repeats and these ranges agree with those in the Technical Standards and Guidelines as summarized in Table 1. Wittenberger et al. also stated that consensus has not yet been reached for the lower limit of the intermediate or gray zone (i.e., 45-54 repeats or 40-54 repeats).

The clinical significance of intermediate and low premutation size alleles is 3 -fold. First, it is the extent to which they may be prone to instability, particularly expansion, in future generations. At the present time, the smallest repeat known to expand to a full mutation in one generation is 59 CGGs. ${ }^{6,7}$ Recognizing this and the fact that there is variation between

Table 1

Comparison of the CGG repeat length ranges for each allelic class as defined by the four reports

\begin{tabular}{lcccc}
\hline Interpretation & $\begin{array}{c}\text { Technical } \\
\text { standards }^{2}\end{array}$ & $\begin{array}{c}\text { Practice } \\
\text { guidelines }^{3}\end{array}$ & $\begin{array}{c}\text { ACOG } \\
\text { committee }_{\text {opinion }}\end{array}$ & $\begin{array}{c}\text { Wittenberger } \\
\text { et al. }\end{array}$ \\
\hline Unaffected & $<45$ & $<41$ & $<41$ & $<45$ \\
$\begin{array}{l}\text { Intermediate, } \\
\text { gray zone }\end{array}$ & $45-54$ & $41-60$ & $41-60$ & $45-54$ \\
$\begin{array}{l}\text { Premutation } \\
\text { Full mutation }\end{array}$ & $55-200$ & $61-200$ & $61-200$ & $55-200$ \\
\hline
\end{tabular}

laboratories and between laboratory methods when determining the exact CGG repeat number, the Laboratory Technical Standards and Guidelines place the boundaries of the premutation range at 55 and 200 CGG repeats. Quality Assurance challenges through the College of American Pathologists have shown that repeat lengths sized using polymerase chain reaction-based techniques can vary by $\pm 3-4$ repeats. The Technical Standards and Guidelines allowed for this variation in choosing 55 repeats as the lower limit of the premutation range to avoid missing any women at risk for having a child with the Fragile X syndrome.

Second, the clinical significance is the extent to which these repeat size alleles increase the risk for premutation-associated Fragile X tremor ataxia syndrome (FXTAS). FXTAS is a lateonset neurodegenerative disorder with predominant features of cerebellar ataxia and intention tremor. Onset is usually in persons older than 50 years. The risk and/or severity of the disorder is associated with repeat size, the highest risk being associated with larger repeats. Among individuals with lateonset cerebellar ataxia, the prevalence of premutation alleles was 13 times greater than expected based on its prevalence in the general population as assessed by a recent meta-analysis. ${ }^{8}$

Lastly, the clinical significance of intermediate/low premutation repeat size alleles is the extent to which they impose a risk for premutation-associated ovarian insufficiency. The prevalence of premature ovarian failure (POF) or cessation of menses before 40 years of age is about $20 \%$, although it is highly associated with repeat size: the risk seems to increase with increasing premutation repeat size between 59 and 99 , thereafter the risk of POF plateaus or even decreases for women with repeat sizes over $100 .{ }^{9}$ Premutation carriers have been identified in about $3 \%$ of women with sporadic POF and in about $12 \%$ of women with familial POF. ${ }^{10}$

Thus, at this point, the risk and/or severity of all three disorders associated with premutation alleles (i.e., instability during transmission, FXTAS and POF) is established for alleles 55-200 repeats. The risk among the alleles in the lower part of this range, 55-70 is significantly lower than that in the upper range, $70-200$, for all three disorders.

Table 2 shows the distribution of repeats among the allelic forms of FMR1 between 41 repeats and 200 repeats as defined in the two conflicting ACMG publications. The table demonstrates that, were genetic counseling to be based on the Practice

\section{Table 2}

Comparison of the clinical interpretation of each allelic class by the two sets of guidelines

\begin{tabular}{lll}
\hline No. repeats & $\begin{array}{c}\text { Interpretation according to } \\
\text { technical standards and } \\
\text { guidelines }\end{array}$ & $\begin{array}{c}\text { Interpretation according to } \\
\text { practice guidelines }\end{array}$ \\
\hline $41-44$ & Unaffected & Intermediate, grayzone \\
$45-54$ & Intermediate, grayzone & Intermediate, grayzone \\
$55-60$ & Premutation & Intermediate, grayzone \\
$61-200$ & Premutation & Premutation \\
\hline
\end{tabular}


Guidelines, individuals with 59 and 60 repeats, who are at risk to have an affected child in the next generation, would not be counseled appropriately. Furthermore, a greater number of patients would be identified to have intermediate or gray zone alleles. As stated above, carrying the label of intermediate or gray zone currently has no established clinical significance and may cause unwarranted concern to families.

In conclusion, the Quality Assurance Committee and the Professional Practice and Guidelines Committee of the ACMG have determined that no changes are required to the ranges published originally in $2001^{1}$ and restated in 2005 in the Technical Standards and Guidelines for Fragile X testing. ${ }^{2}$ The ACMG Quality Assurance Committee and the Professional Practice and Guidelines Committee recommend that the following ranges for CGG repeat size be used in the laboratory as well as in clinical practice:

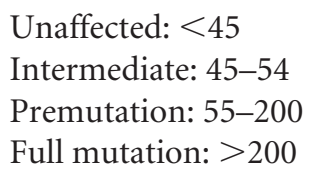

Kathryn E. Kronquist, PhD, FACMG Molecular/Genetics Department Kaiser Permanente Regional Reference Laboratory Denver, Colorado

Stephanie L. Sherman, PhD, FACMG Department of Human Genetics Emory University Atlanta, Georgia
Elaine B. Spector, PhD, FACMG

UC Denver DNA Diagnostic Laboratory

University of Colorado Denver

School of Medicine

Aurora, Colorado

\section{References}

1. Maddalena A, Richards CS, McGinniss MJ, et al. Technical standards and guidelines for fragile X: the first of a series of disease-specific supplements to the Standards and Guidelines for Clinical Genetics Laboratories of the American College of Medical Genetics. Quality Assurance Subcommittee of the Laboratory Practice Committee. Genet Med 2001;3:200-205.

2. Spector EB, Kronquist KE. Fragile X: technical standards and guidelines. ACMG standards and guidelines for clinical genetics laboratories, 2005. Available at: www.acmg.net.

3. Sherman S, Pletcher BA, Driscoll DA. Fragile X syndrome: diagnostic and carrier testing. Genet Med 2005;7:584-587.

4. ACOG committee opinion No. 338: Screening for Fragile X syndrome. Obstet Gynecol 2006;107:1483-1485.

5. Wittenberger MD, Hagerman RJ, Sherman SL, et al. The FMR1 premutation and reproduction. Fertil Steril 2007;87:456-465.

6. Hagerman PJ, Hagerman RJ. The fragile-X premutation: a maturing perspective. Am J Hum Genet 2004;74:805-816.

7. Nolin SL, Brown WT, Glicksman A, et al. Expansion of the fragile X CGG repeat in females with premutation or intermediate alleles. Am J Hum Genet 2003;72:454464.

8. Jacquemont S, Leehey MA, Hagerman RJ, et al. Size bias of fragile X premutation alleles in late-onset movement disorders. J Med Genet 2006;43:804-809.

9. Ennis S, Ward D, Murray A. Nonlinear association between CGG repeat number and age of menopause in FMR1 premutation carriers. Eur J Hum Genet 2006;14: 253-255.

10. Sherman SL, Taylor K, Allen EG. FMR1 premutation: a leading cause of inherited ovarian dysfunction. In: Arrieta I, Penagarikano O, et al., editors. Fragile sites: new discoveries and changing perspectives. Hauppauge: Nova Science Publishers, Inc., 2007:229-320. 